\title{
Effect of under-bump-metallization structure on electromigration of Sn-Ag solder joints
}

\author{
Hsiao-Yun Chen, Min-Feng Ku and Chih Chen* \\ Department of Materials Science and Engineering, National Chiao Tung University, \\ Hsin-chu 30010, Taiwan, Republic of China
}

(Received August 31, 2011, Revised March 8, 2012, Accepted March 9, 2012)

\begin{abstract}
The effect of under-bump-metallization (UBM) on electromigration was investigated at temperatures ranging from $135^{\circ} \mathrm{C}$ to $165^{\circ} \mathrm{C}$. The UBM structures were examined: $5-\mu \mathrm{m}-\mathrm{Cu} / 3-\mu \mathrm{m}-\mathrm{Ni}$ and $5 \mu \mathrm{m} \mathrm{Cu}$. Experimental results show that the solder joint with the $\mathrm{Cu} / \mathrm{Ni} \mathrm{UBM}$ has a longer electromigration lifetime than the solder joint with the $\mathrm{Cu}$ UBM. Three important parameters were analyzed to explain the difference in failure time, including maximum current density, hot-spot temperature, and electromigration activation energy. The simulation and experimental results illustrate that the addition $3-\mu \mathrm{m}-\mathrm{Ni}$ layer is able to reduce the maximum current density and hot-spot temperature in solder, resulting in a longer electromigration lifetime. In addition, the $\mathrm{Ni}$ layer changes the electromigration failure mode. With the $5 \mu \mathrm{m} \mathrm{Cu} \mathrm{UBM}$, dissolution of $\mathrm{Cu}$ layer and formation of $\mathrm{Cu}_{6} \mathrm{Sn}_{5}$ intermetallic compounds are responsible for the electromigration failure in the joint. Yet, the failure mode changes to void formation in the interface of $\mathrm{Ni}_{3} \mathrm{Sn}_{4}$ and the solder for the joint with the $\mathrm{Cu} / \mathrm{Ni} \mathrm{UBM}$. The measured activation energy is $0.85 \mathrm{eV}$ and $1.06 \mathrm{eV}$ for the joint with the $\mathrm{Cu} / \mathrm{Ni}$ and the $\mathrm{Cu} \mathrm{UBM}$, respectively.
\end{abstract}

Keywords: electromigration; solder joints

\section{Introduction}

Owing to the continuous shrinking flip-chip solder joint, the electromigration has been recognized as an important reliability issuse (Tu 2007, Chen et al. 2010, Tu et al. 2001, Zeng and Tu 2002, Xu et al. 2006, Zang et al. 2006). Serious current crowding effect causes void formation or enhances dissolution of the thick-film under-bump metallization (UBM) in flip-chip solder joints (Tu 2003, Choi et al. 2003, Nah et al. 2003, Shao et al. 2004, Lin et al. 2005, Lin et al. 2006). Void formation and the consumption of UBM formed intermetallic compounds (IMCs) inside the solder bump resulted serious reliability issues in flip-chip solder joints. As the result, the selection of an appropriate UBM layer becomes an important process for developing a reliable flip-chip joint. Especially with the adoption of the lead-free solders due to environmental concerns, the fast dissolution rate of UBM into $\mathrm{Sn}$-based $\mathrm{Pb}$-free solder induces the serious IMC formation (Xu et al. 2008).

In order to minimize the current crowding effect, thick $\mathrm{Cu}$ UBM has been chosen for SnAg solder

*Corresponding author, Professor, E-mail: chih@cc.nctu.edu.tw 
joints (Nah et al. 2006, Liang et al. 2006a). The electromigration resistance was significantly improved after adopting a thick $\mathrm{Cu}$ UBM to relieve current crowding effect in solder (Nah et al. 2006). The electromigration can be avoided by reducing the current crowding effect in the solder region. By utilizing simulation results, Liang et al. found that joints with a thicker $\mathrm{Cu}$ UBM exhibited a lower maximum current density and hot spot temperature; the current crowding and local Joule heating effect vanished when the Cu UBM thickness was over than $50 \mu \mathrm{m}$ (Liang et al. 2006a). Moreover, Lin et al. also reported that the joints with a thicker Ni UBM tend to have a longer electromigration lifetime (Lin et al. 2008). The combination of current crowding and local Joule heating near the entrance point induced asymmetric of consumption Ni UBM. Therefore, once the Ni UBM is exhausted in a certain region, the region become nonconductive and results in failure. On the other hand, $\mathrm{Ni}$ is much more resistant to dissolution into solder and is less susceptible to fail through dissolution of UBM layer (Lin et al. 2006). Based on their observations, it is a reasonable assumption that the design of a UBM structure is critical for the lifetime of solder joints. Therefore, adopting thick $\mathrm{Cu}$ and $\mathrm{Ni}$ UBMs should provide an opportunity to extend the electromigration lifetime of solder joint.

According to Choi et al. (2003) the mean-time-to-failure (MTTF) of solder joints can be represent as

$$
\mathrm{MTTF}=A \frac{1}{(c j)^{n}} \exp \left[\frac{Q}{k(T+\Delta T)}\right]
$$

where $A$ is constant, $j$ is current density, $n$ is a model parameter for current density, $Q$ is electromigration activation energy, $c$ is a current density factor to modify the serious current crowding effect in solder joints, $k$ is Boltzmann's constant, $T$ is average bump temperature without considering Joule heating effect, and $\Delta T$ is the additional temperature increase due to the Joule heating effect during electromigration tests. Therefore, three major parameters that affect electromigration lifetime are current density, temperature and activation energy.

However, the effect of the UBM structure on failure mechanism and failure time in $\mathrm{Pb}$-free flipchip solder joints has not been systematically investigated yet. In the paper, we fabricated two sets of electromigration tested samples with the same wiring layout. The only difference is UBM structure: one set with $5-\mu \mathrm{m} \mathrm{Cu} \mathrm{UBM}$ and the other with additional $3-\mu \mathrm{m}$ Ni layers in $5 \mu \mathrm{m} \mathrm{Cu}$ UBM. Temperature distributions were measured by infrared (IR) microscopy. Finite element analysis (FEA) was carried out to simulate the current density distribution in the solder joints. This research provides a systematical study on the effect of UBM structure on electromigration behaviors.

\section{Experimental}

In order to investigate the electromigration, a special layout of Kelvin bump probes was adopted (Chang et al. 2006), as illustrated schematically in Fig. 1(a). On the chip side, a $0.3 \mu \mathrm{m}$ Ti layer was sputtered as an adhesion/diffusion-barrier layer between the UBM and the Al trace which connects four bumps together. Four solder bumps were labeled as $B 1$ to $B 4$, and the three Al traces were denoted as $T 1$ to $T 3$. Eutectic SnAg alloys were adopted as the solder bump materials. The bump height is approximately $70 \mu \mathrm{m}$ and the diameter is about $150 \mu \mathrm{m}$. Two sets of samples were fabricated: one with $5-\mu \mathrm{m} \mathrm{Cu} / 3-\mu \mathrm{m}$ Ni UBMs; and the other with $5-\mu \mathrm{m} \mathrm{Cu} \mathrm{UBMs} \mathrm{as} \mathrm{shown} \mathrm{in} \mathrm{Fig.}$ 


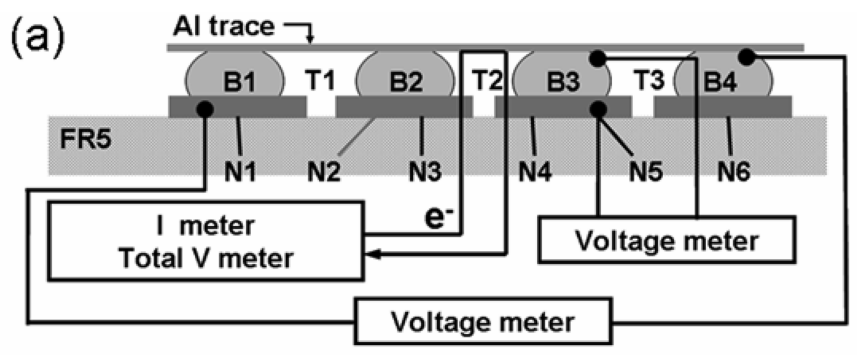

(b)

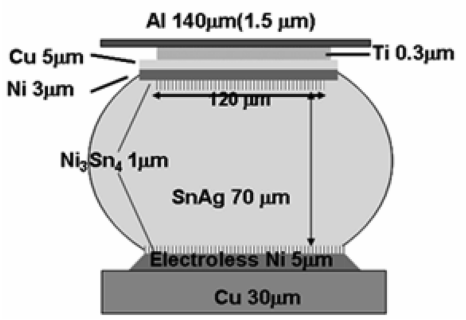

(c)

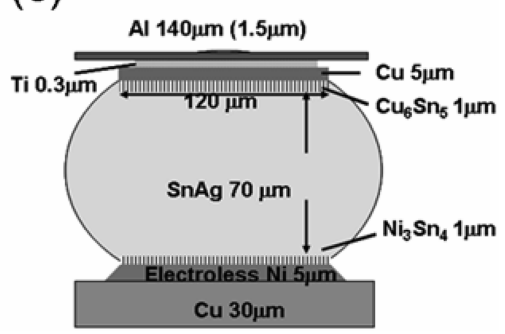

Fig. 1 Cross-sectional schematic of the electomigration layout design; An Al trace connected all four solder bumps together; (a) setup for electromigration test, (b) SnAg solder with the $\mathrm{Cu} / \mathrm{Ni} \mathrm{UBM}$, and (c) SnAg solder with the Cu UBM (Chen and Chen 2010)

1(b) and 1(c), respectively. The solder bumps were joined to FR5 substrates, which have a glass transition temperature of $170^{\circ} \mathrm{C}$ and were fabricated by New-Heart Technology, Co. Ltd. The dimension of $\mathrm{Al}$ trace in the chip side was $100 \mu \mathrm{m}$ wide and $1.5 \mu \mathrm{m}$ thick, while the dimension of the $\mathrm{Cu}$ lines on the substrate was $25 \mu \mathrm{m}$ thick and $100 \mu \mathrm{m}$ wide. On the substrate side, six $\mathrm{Cu}$ nodes were fabricated and labeled as Node $N 1$ through $N 6$. By these six nodes, the resistance for the middle segment of the $\mathrm{Al}$ trace, bump $B 2$ and bump $B 3$ can also be monitored.

IR microscopy was employed to measure the temperature of the hot spot during current stressing. Prior to current stressing, the emissivity of the specimen was calibrated at $100^{\circ} \mathrm{C}$. After calibration process, a desired current was applied through Bump 2 and Bump 3. The temperature measurement was performed to record the temperature distribution (map) at the steady state. Current stressing was carried out at different temperatures on $135^{\circ} \mathrm{C}, 150^{\circ} \mathrm{C}$ to $165^{\circ} \mathrm{C}$ on a hot plate. Electromigration tests were performed at the current density of $7.0 \times 10^{3} \mathrm{~A} / \mathrm{cm}^{2}$ for $\mathrm{Cu}$ UBM system, and $7.9 \times 10^{3} \mathrm{~A} / \mathrm{cm}^{2}$ for $\mathrm{Cu} / \mathrm{Ni}$ UBM system. When firstly stressed under $7.9 \times 10^{3} \mathrm{~A} / \mathrm{cm}^{2}$ for $\mathrm{Cu}$ UBM system, the failure time was too short at $165^{\circ} \mathrm{C}$. Therefore, we reduced the current density for solder joints with $\mathrm{Cu}$ UBMs to $7.0 \times 10^{3} \mathrm{~A} / \mathrm{cm}^{2}$.

The temperatures in the solder joints could be mapped by a QFI thermal IR microscope with $0.1^{\circ} \mathrm{C}$ temperature resolution and $2 \mu \mathrm{m}$ spatial resolution. The microstructure of the interfacial regions between the solders and UBMs were examined by a scanning electron microscope (SEM, JEOL 6500). Moreover, the compositions of the solder joints and the IMCs were analyzed quantitatively by energy dispersive spectroscopy (EDX).

Three-dimensional (3D) FEA was performed to simulate the current-density distribution in the solder joint. The dimensions of the $\mathrm{Al}$ trace, pad opening, and $\mathrm{Cu}$ line were identical as the 
Table 1.

\begin{tabular}{ccc}
\hline \hline Materials & Resistivity $(\mu \Omega \cdot \mathrm{cm})$ & Thermal conductivity $(\mathrm{W} / \mathrm{m} \cdot \mathrm{K})$ \\
\hline $\mathrm{Al}$ & 3.2 & 238 \\
$\mathrm{Cu}$ & 1.7 & 403 \\
$\mathrm{Ni}$ & 6.8 & 76 \\
$\mathrm{Sn} 3.5 \mathrm{Ag}$ & 12.3 & 33 \\
$\mathrm{EL}-\mathrm{Ni}$ & 70 & 76 \\
$\mathrm{Cu}_{6} \mathrm{Sn}_{5}$ & 17.5 & 34.1 \\
$\mathrm{Ni}_{3} \mathrm{Sn}_{4}$ & 28.5 & 19.6 \\
\hline
\end{tabular}
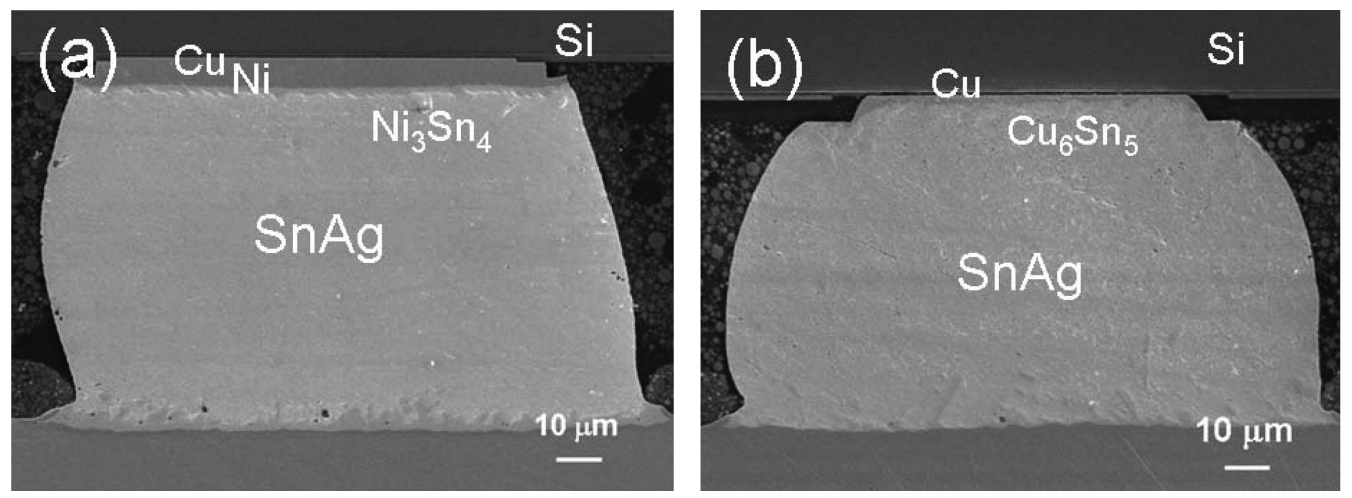

Fig. 2 Cross-sectional SEM images for solder bump before current stressing; (a) SnAg solder with the $\mathrm{Cu} / \mathrm{Ni}$ UBM (b) SnAg solder with the Cu UBM (Chen and Chen 2010)

dimension of the flip-chip samples. The IMC formed between the UBM and the solder was also considered in the simulation models. The Ni layers on the chip and the substrate sides were assumed to consume $0.5 \mu \mathrm{m}$ and form $1.0 \mu \mathrm{m}$ of $\mathrm{Ni}_{3} \mathrm{Sn}_{4}$ IMC. Layered IMCs, $\mathrm{Ni}_{3} \mathrm{Sn}_{4}$, were used in this simulation for the $\mathrm{Ni}_{3} \mathrm{Sn}_{4}$ to avoid difficulty in mesh. On the other hand, $1.0 \mu \mathrm{m} \mathrm{Cu} \mathrm{Cu}_{6} \mathrm{Sn}_{5}$ formed at the chip side on $\mathrm{Cu}$ UBM system. The resistivities and the thermal conductivities of the materials used in the simulation are listed in Table 1 (Chang et al. 2006). The model used in this study was SOLID69 eight-node hexahedral coupled field element using ANSYS simulation software. The size of the element in the solder bump was $3.0 \mu \mathrm{m}$.

\section{Results and Discussion}

Figs. 2(a) and 2(b) show the cross-sectional SEM image of the SnAg3.5 solder joint with the $\mathrm{Cu} /$ $\mathrm{Ni}$ and $\mathrm{Cu}$ UBM before current stressing, respectively. Bump resistance was increased due to the void formation and microstructure changes during electromigration can be precisely measured by using Kelvin bump probes. Fig. 3 shows resistance changes of the bump resistance as a function of stressing time. We defined the failure criteria as resistance of Bump 3 increased $20 \%$ of its original value in this paper. After $25 \mathrm{~h}$ current stressing under $7.0 \times 10^{3} \mathrm{~A} / \mathrm{cm}^{2}$ at $150^{\circ} \mathrm{C}$, in $\mathrm{Cu} \mathrm{UBM}$ system, 

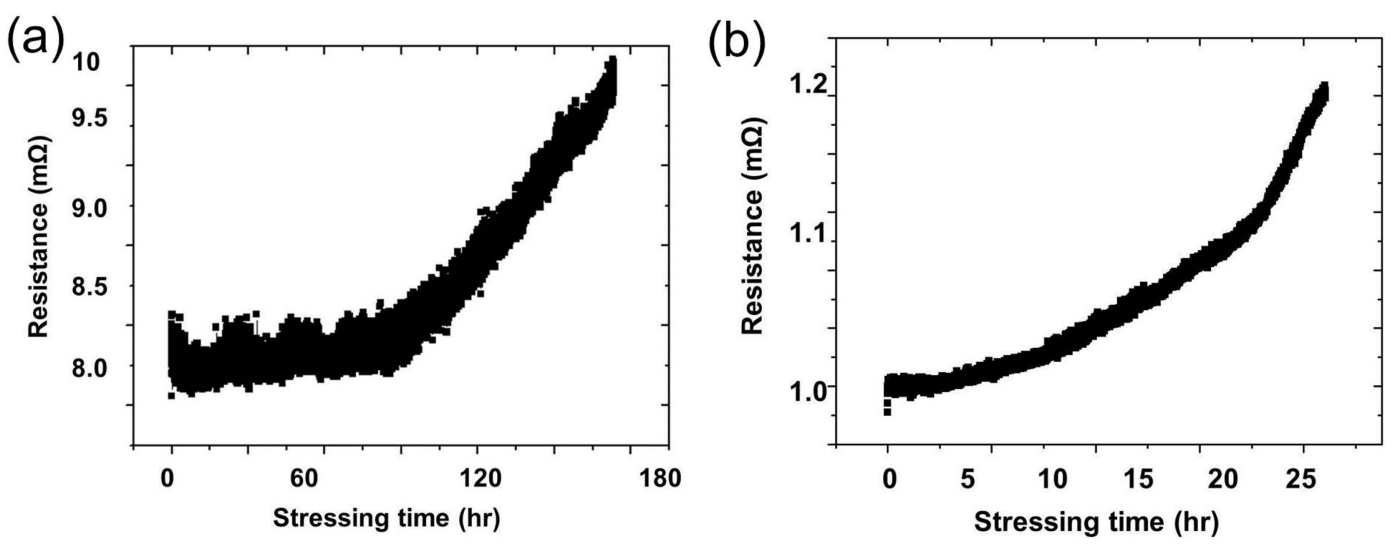

Fig. 3 The measured resistance for Bump 3 as a function of stressing time powered by (a) $0.9 \mathrm{~A}\left(7.9 \times 10^{3} \mathrm{~A} /\right.$ $\left.\mathrm{cm}^{2}\right)$ at $150^{\circ} \mathrm{C}$ for the $\mathrm{Cu} / \mathrm{Ni}$ UBM system, (b) $0.8 \mathrm{~A}\left(7.0 \times 10^{3} \mathrm{~A} / \mathrm{cm}^{2}\right)$ at $150^{\circ} \mathrm{C}$ for the $\mathrm{Cu}$ UBM system (Chen and Chen 2010)
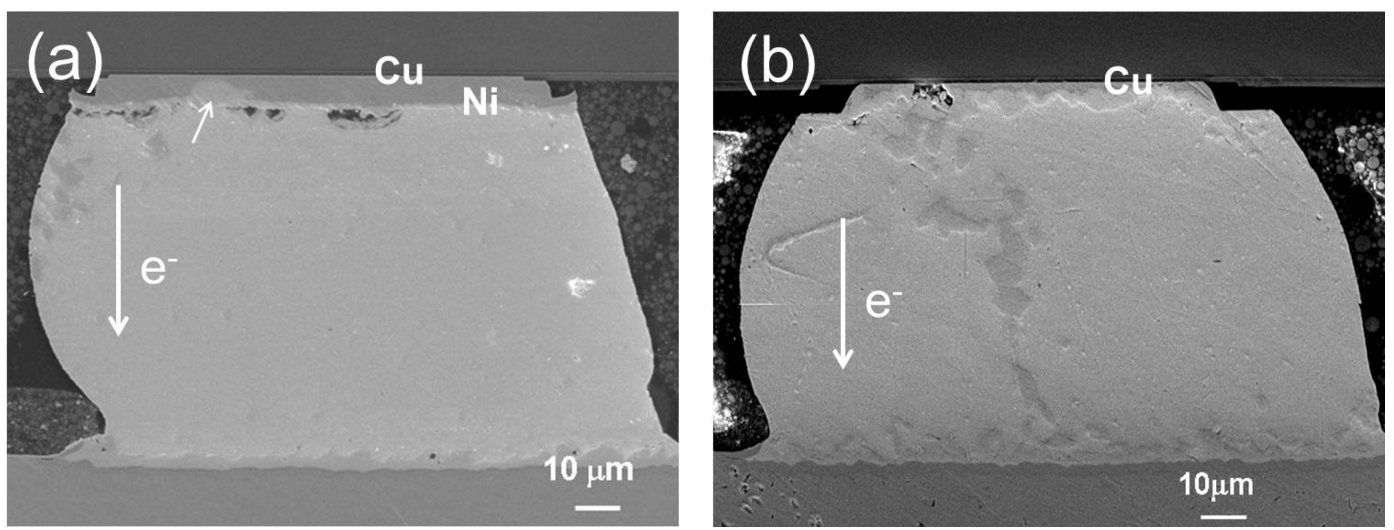

Fig. 4 Cross-sectional SEM images for Bump 3 after its resistance increase $20 \%$ of its original value; (a) SnAg bump with the $\mathrm{Cu} / \mathrm{Ni}$ UBM after stressed by $7.9 \times 10^{3} \mathrm{~A} / \mathrm{cm}^{2}$ at $150^{\circ} \mathrm{C}$; (b) $\mathrm{SnAg}$ bump with the $\mathrm{Cu}$ UBM after stressed by $7.0 \times 10^{3} \mathrm{~A} / \mathrm{cm}^{2}$ at $150^{\circ} \mathrm{C}$ (Chen and Chen 2010)

as shown in Fig. 3(b), the resistance of Bump 3 reached the failure criteria. Yet, it took $160 \mathrm{~h}$ for $\mathrm{Cu} / \mathrm{Ni}$ system under a higher testing condition of $7.9 \times 10^{3} \mathrm{~A} / \mathrm{cm}^{2}$ as shown in Fig. 3(a). The resistance in Fig. 3(a) rose slowly at the initial stage, the stressing time within $85 \mathrm{~h}$, but increased dramatically afterwards. On the other hand, for the solder joint with $\mathrm{Cu}$ UBM, the resistance in Fig. 3(b) increased gradually. The two slopes in Fig. 3(a) may represent different stages, for instance, void nucleation and the propagation. Under our testing conditions, $\mathrm{Cu} / \mathrm{Ni} \mathrm{UBM}$ system has the longer failure time compared with the $\mathrm{Cu}$ UBM system. The corresponding microstructure changes are shown in Figs. 4(a) and 4(b). Void formation was clearly observed near the entrance point in both $\mathrm{Cu} / \mathrm{Ni}$ and $\mathrm{Cu}$ systems when the resistance of Bump 3 reached to 1.2 times of its original value. The main difference between these two systems is the void location. For $\mathrm{Cu} / \mathrm{Ni}$ UBM system, the voids appeared near the interface between solders and the $\mathrm{Ni}_{3} \mathrm{Sn}_{4}$; however, voids formed near the interface of the $\mathrm{Cu}$ UBM and the $\mathrm{Al}$ trace pad after the consumption of thick $\mathrm{Cu}$ UBM at the 
(a)

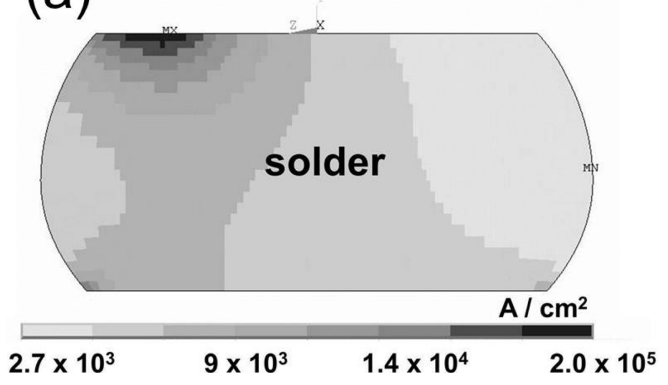

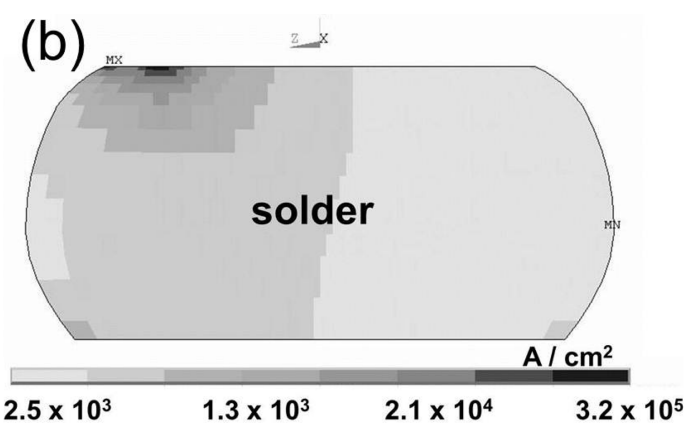

Fig. 5 (a) Cross-sectional view of simulated current density distribution in $\mathrm{Cu} / \mathrm{Ni}$ UBM system; (b) in $\mathrm{Cu}$ UBM system; The maximum current density is $2.0 \times 10^{5}$ and $3.2 \times 10^{5} \mathrm{~A} / \mathrm{cm}^{2}$ for the joint with the $\mathrm{Cu} /$ $\mathrm{Ni}$ and the $\mathrm{Cu}$ UBM, respectively (Chen and Chen 2010)

upper-left corner, which is the current crowding region.

In $\mathrm{Cu} / \mathrm{Ni}$ UBM system, voids first formed at the interface between the $\mathrm{Ni}_{3} \mathrm{Sn}_{4}$ IMCs and the solder, and then propagated along the interface, which is known as the pancake-type void (Zang et al. 2006, Yeh et al. 2002). However, the voids on the present study are not continuous. It is speculated that when some voids formed, current crowding may become serious at the neighboring UBM. The larger current density may enhance dissolution of the Ni UBM. Once the Ni UBM is dissolved, the $\mathrm{Cu}$ atoms can diffuse into solder very easily to form $\mathrm{Cu}-\mathrm{Ni}$-Sn IMCs. The location where the upper $\mathrm{Cu}$ UBM dissolved to form IMCs was pointed out by the arrow in Fig. 4(a). The voids propagated along the interface beneath IMC at some place, which can be observed at the middle of the UBM and solder interface. However, in the single layer $\mathrm{Cu}$ UBM system, the $\mathrm{Cu}$ UBMs first dissolved at very high rate by interstitial diffusion (Dvson et al. 1967). It is reported that the $\mathrm{Cu}_{6} \mathrm{Sn}_{5}$ IMCs and Ti have high interfacial energy (Liu et al. 1996). Thus, as soon as $\mathrm{Cu}$ is consumed, the adhesion of $\mathrm{Cu}_{6} \mathrm{Sn}_{5}$ and $\mathrm{Ti}$ become very poor, which will facilitate the void formation at the interface during current stressing. The fast dissolution causes the poor interface contact and at least $5 \sim 7 \%$ bump resistance was increased. Therefore, electromigration lifetime becomes shorter in $\mathrm{Cu}$ single layer UBM system. Furthermore, the high $\mathrm{Cu}$ solubility in $\mathrm{Pb}$-free solders may also facilitate the electromigration of $\mathrm{Cu}$ to enhance the formation of $\mathrm{Cu}-\mathrm{Sn}$ IMCs and resulted in a shorter lifetime of $\mathrm{Cu}$ UBM system. It was reported that the solubility of $\mathrm{Cu}$ in eutectic $\mathrm{SnPb}$ at $220^{\circ} \mathrm{C}$ is $0.18 \mathrm{wt} . \%$, whereas it reaches $1.54 \mathrm{wt} . \%$ in $\mathrm{Pb}$-free solders at $260^{\circ} \mathrm{C}$ (Zeng and $\mathrm{Tu}$ 2002).

If we continue to stress the two sets of samples at the above conditions until open failure, it revealed $1200 \mathrm{~h}$ for the $\mathrm{Cu} / \mathrm{Ni}$ system; whereas it only took $407 \mathrm{~h}$ to do so. This large difference indicates that $\mathrm{SnAg}$ solder joints with $\mathrm{Cu} / \mathrm{Ni}$ UBMs certainly increases the failure time.

As delineated by Eq. (1), three important parameters can influence the electromigration lifetime of solder joints, including current and temperature distribution, as well as activation energy. We will examine how they affect the electromigration lifetime and the failure mode systematically. The solder joint with the $\mathrm{Cu}$ UBM has higher maximum current density than that in the solder joint with the $\mathrm{Cu} / \mathrm{Ni}$ UBM. Figs. 5(a) and 5(b) show the distribution of current density in the solder bump when applied by $7.9 \times 10^{3} \mathrm{~A} / \mathrm{cm}^{2}$. The current density distributions in the $\mathrm{Al}$ trace, UBM, and $\mathrm{Cu}$ trace are not shown here, since solder is the most vulnerable material during electromigration test. The electron flow enters from the upper-left corner into both bumps, and thus the maximum current 

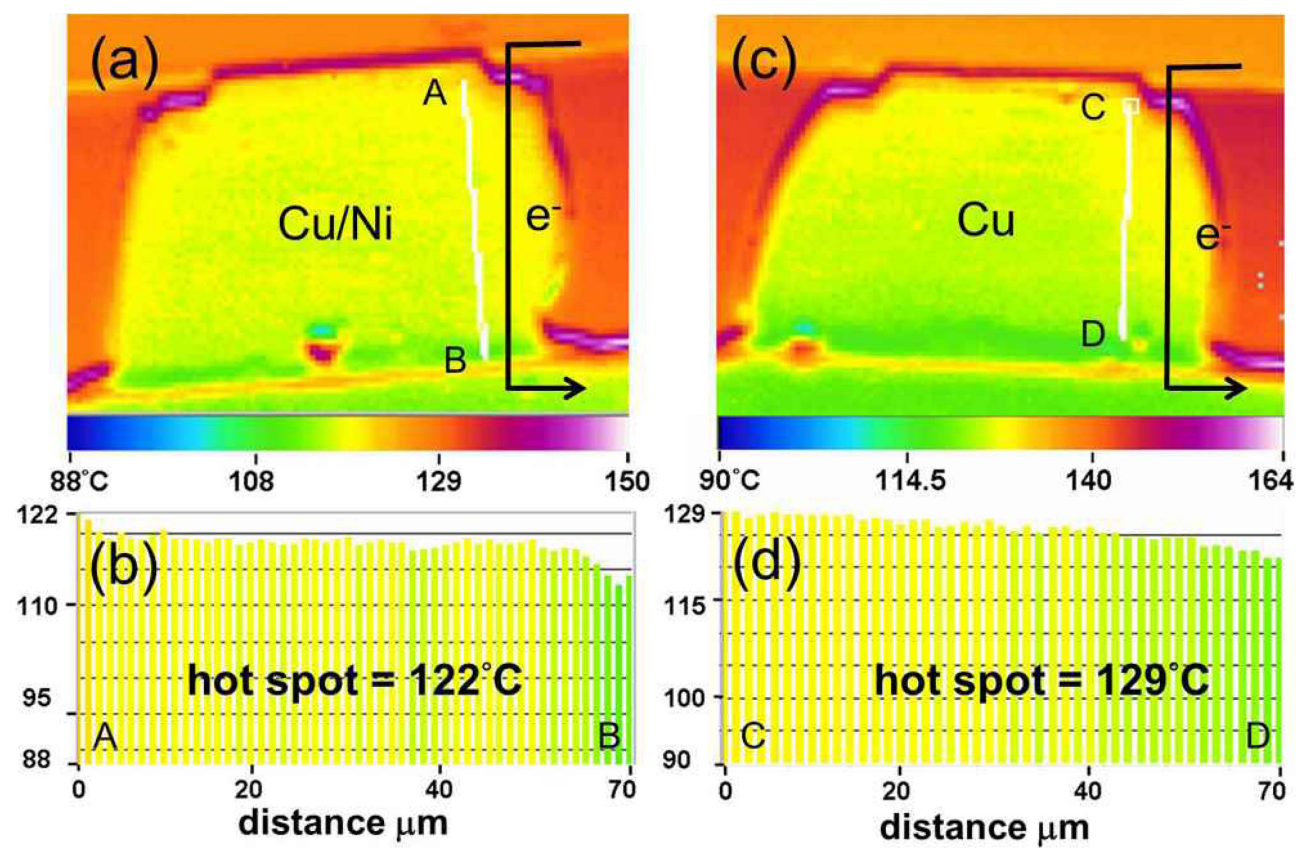

Fig. 6 IR images showing the temperature distribution and the hot-spot near the entrance point the $\mathrm{SnAg}$ bump in (a) the $\mathrm{Cu} / \mathrm{Ni}$ system; (b) the temperature profile along the line $\overline{\mathrm{AB}}$ in (a); (c) the $\mathrm{Cu}$ system; (d) the temperature profile along the line $\overline{\mathrm{CD}}$ in (c). The applied current is $0.9 \mathrm{~A}$ on a hot plate at $100^{\circ} \mathrm{C}($ Chen and Chen 2010)

density occurs there. That is also the main reason why electromigration damage started at those locations, as illustrated in Figs. 4(a) and 4(b). Furthermore, the maximum current density is $2.0 \times 10^{5} \mathrm{~A} / \mathrm{cm}^{2}$ for the solder joint with $\mathrm{Cu} / \mathrm{Ni}$ UBM. However, it is $3.2 \times 10^{5} \mathrm{~A} / \mathrm{cm}^{2}$ for the solder joint with the $\mathrm{Cu}$ UBM. Two reasons contribute to the low current crowding effect in the solder joint with the $\mathrm{Cu} / \mathrm{Ni} \mathrm{UBM}$. First, the additional 3- $\mu \mathrm{m}$ Ni layer helps to keep solder away from the high current density region. As the current drifts downwards, it spreads out simultaneously. Liang et al. reported that a thick UBM reduces the current density in the solder bump (Liang et al. 2006a), because the solder stays away from the current crowding region. Second, the resistive $\mathrm{Ni}_{3} \mathrm{Sn}_{4} \mathrm{IMC}$ also helps to relieve current crowding effect. The resistivity of $\mathrm{Ni}_{3} \mathrm{Sn}_{4} \mathrm{IMC}$ is $28.5 \mu \Omega \cdot \mathrm{cm}$, which is higher than that of $\mathrm{Cu}_{6} \mathrm{Sn}_{5}$ IMC $(17.5 \mu \mathrm{m} \cdot \mathrm{cm})$. It is reported a resistive layer may help to reduce the current crowding effect (Liang et al. 2006b). Yet, the former should have larger contribution on relieving the current crowding effect than the later, because the resistivity of the two IMCs does not differ too much. Therefore, compare with the solder joint with the $\mathrm{Cu}$ UBM, the solder joint with the $\mathrm{Cu} / \mathrm{Ni} \mathrm{UBM}$ has a lower maximum current density, resulting in a higher electromigration resistance.

Chiu et al. reported that a hot spot exists in the solder when the solder joint was subjected to stressing at a high current density. For measuring temperature distribution in the solder joint, IR microscopy was employed to measure the temperature distribution in the solder joints. Fig. 6(a) shows the cross-sectional IR image for the solder joint with the $\mathrm{Cu} / \mathrm{Ni} \mathrm{UBM}$ stressed at $0.9 \mathrm{~A}$ at $100^{\circ} \mathrm{C}$. It is clear that the temperature on the chip side is higher than that on the substrate side, 


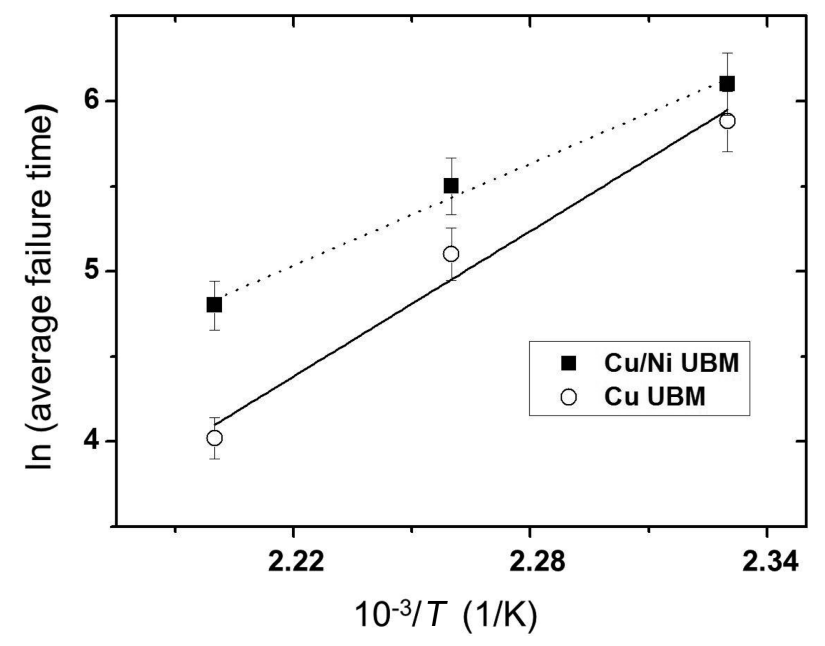

Fig. 7 Plots of average failure time against $10^{-3} / T$ for eutectic SnAg solder joints with the $\mathrm{Cu} / \mathrm{Ni} \mathrm{UBM}$ and with the $\mathrm{Cu}$ UBM (Chen and Chen 2010)

which is attributed that the Al trace on the chip side serves as the major heat generator in the structure. The current entered the solder bump from the upper right corner, resulting in a serious crowding effect there. Therefore, the local Joule heating heats up the solder there. Fig. 6(b) presents the temperature profile along the white line $\overline{\mathrm{AB}}$ in Fig. 6(a). The line starts from the solder close to $\mathrm{Ni}_{3} \mathrm{Sn}_{4} \mathrm{IMCs}$. The measured hot-spot temperature is $122^{\circ} \mathrm{C}$, which is $22^{\circ} \mathrm{C}$ higher than the hot plate temperature due to Joule heating effect. Similarly, Fig. 6(c) shows the temperature map of the solder joint with the $\mathrm{Cu}$ UBM and Fig. 6(d) depicts the temperature profile along the black line $\overline{\mathrm{CD}}$ in Fig. 6(c). The hot-spot temperature is as high as $129^{\circ} \mathrm{C}$ at the solder close to the $\mathrm{Cu}_{6} \mathrm{Sn}_{5}$ IMCs. Two reasons may cause the higher hot-spot temperature in the solder joint with the $\mathrm{Cu}$ UBM. First, the solder in this joint is close to the major heating source, the Al trace. Second, as shown in Figs. 5(a) and 5(b), the local current density in the solder with the $\mathrm{Cu}$ UBM is 1.6 times larger than that with $\mathrm{Cu} / \mathrm{Ni}$ UBM. The local Joule heating power, $P$, can be expressed as

$$
P=j^{2} \rho V
$$

Where $j$ is local current density, $\rho$ is resistivity, and $V$ is volume. Therefore, the local Joule heating power in the joint with the $\mathrm{Cu}$ UBM is approximately 2.5 times larger than that with the $\mathrm{Cu} / \mathrm{Ni}$ UBM. The hot-spot temperature is higher in the solder with the $\mathrm{Cu}$ UBM, resulting in a higher diffusivity and faster failure during electromigration test.

The measured activation energy of electromigration also depends on the UBM. Because Joule heating effect takes place seriously in solder joints, measuring the real stressing temperature is critical in obtaining accurate value of activation energy. The temperature coefficient of resistivity of $\mathrm{Al}$ traces was used to monitor the real temperatures in the solder joints subjected to current stressing.

The experimental details were reported in our previous publication (Chen and Chen 2010). Table II lists the average time at various temperatures for the solder joints. Fig. 7 shows the plots of average failure time vs. with $10^{-3} / \mathrm{T}$ for the $\mathrm{Cu} / \mathrm{Ni}$ and $\mathrm{Cu}$ system, respectively. The measured activation 
energy is $0.85 \mathrm{eV}$ and $1.06 \mathrm{eV}$ for the solder joints with $\mathrm{Cu} / \mathrm{Ni}$ and the $\mathrm{Cu} \mathrm{UBM}$ respectively. It is known that the activation energy is $1.05 \mathrm{eV}$ for that growth of $\mathrm{Cu}_{6} \mathrm{Sn}_{5}$ IMC between $\mathrm{SnAg}$ solder and $\mathrm{Cu}$ (Lee et al. 2002). In the present study, we observed that the failure mechanism of electromigration in the $\mathrm{Cu}-\mathrm{Sn} \mathrm{IMC}$ formation, which is in agreement with the measured activation energy. On the other hand, the electromigration failure mechanism is mainly void formation in the interface of the $\mathrm{Ni}_{3} \mathrm{Sn}_{4}$ and the solder, and the electromigration activation energy is $0.85 \mathrm{eV}$.

Among the three parameters, the joint with the $\mathrm{Cu} / \mathrm{Ni}$ UBM has a lower maximum current density and lower hot-spot temperature than the joint with $\mathrm{Cu}$ UBM. However, the activation energy in the $\mathrm{Cu} / \mathrm{Ni} \mathrm{UBM}$ is lower than that in the $\mathrm{Cu}$ UBM. Although how to modify MTTF equation for the solder joints is still debating (Lai and Kao 2006), it is true that a lower maximum current density and a hot-spot temperature render a longer electromigration lifetime. Because the electron wind force is lower at a lower current density and the diffusion slows down at low temperature. On the other hand, the joint with the $\mathrm{Cu} / \mathrm{Ni} \mathrm{UBM}$ has a lower activation energy of $0.85 \mathrm{eV}$, which will have a shorter electromigration lifetime if other parameters are fixed, as described by Eq. (1). According to the experimental results listed in Table II, the average failure time for the $\mathrm{Cu} / \mathrm{Ni}$ joint is longer than that of the $\mathrm{Cu}$ joint in all test conditions. The results indicate that the electrical and thermal characteristics dominate the electromigration failure time. However, it is noteworthy that when the thickness of the $\mathrm{Cu}$ UBM increases, the maximum current density and hot-spot temperature would decrease (Liang et al. 2006a). The electromigration lifetime for the joint with a thick $\mathrm{Cu}$ UBM would increase. Therefore, the UBM thickness plays a crucial role on the failure time of solder joints.

\section{Conclusions}

In summary, we have investigated the effect of UBM structure on electromigration failure mechanism and failure time systematically. Three major parameters, current density distribution, hot-spot temperature, and activation energy were examined. The solder joints with $\mathrm{Cu} / \mathrm{Ni} \mathrm{UBM}$ have lower maximum current density and hot-spot temperature in solder, which contribute to the longer electromigration lifetime. The failure mode for the $\mathrm{Cu} / \mathrm{Ni}$ joints was void formation along the interface of the $\mathrm{Ni}_{3} \mathrm{Sn}_{4} \mathrm{IMC}$ and the solder.

\section{Acknowledgements}

The authors would like to thank the National Science Council of R.O.C. for financial support through grant No. 98-2221-E-009-036-MY3.

\section{References}

Chang, Y.W., Liang, S.W. and Chen, C. (2006) "Study of void formation due to electromigration in flip-chip solder joints using Kelvin bump probes”, Appl. Phys. Lett., 89(3), 032103.

Chen, C., Tong, H.M. and Tu, K.N. (2010), "Electromigration and thermomigration in Pb-Free flip-chip solder joints", Annu. Rev. Mater. Res., 40, 531-555. 
Chen, H.Y. and Chen, C. (2010), "Measurement of electromigration activation energy in eutectic $\mathrm{SnPb}$ and $\mathrm{SnAg}$ flip-chip solder joints with $\mathrm{Cu}$ and Ni under-bump metallization", J. Mater. Res., 25(9), 1847-1853.

Choi, W.J., Yeh, E.C.C. and Tu, K.N. (2003), "Mean-time-to-failure study of ip chip solder joints on $\mathrm{Cu} / \mathrm{Ni}(\mathrm{V}) /$ Al thin-lm under-bump-metallization", J. Appl. Phys., 94(9), 5665-5671.

Dvson, B.F., Anthony, T.R. and Turnbull, D. (1967), "Interstitial diffusion of copper in Tin", J. Appl. Phys., 38(8), 3408-3409.

Lai, Y.S. and Kao, C.L. (2006) "Calibration of electromigration reliability of flip-chip packages by electrothermal coupling analysis", J. Electron. Mater., 35(5), 972-935.

Lee, T.Y., Choi, W.J., Tu, K.N., Jang, J.W., Kuo, S.M., Lin, J.K., Frear, D.R., Zeng, K. and Kivilahti, J.K. (2002), "Morphology, kinetics, and thermodynamics of solid-state aging of eutectic PbSn and Pb-free solders (Sn-3.5Ag, Sn-3.8Ag-0.7Cu and $\mathrm{Sn}-0.7 \mathrm{Cu}$ ) on Cu", J. Mater. Res., 17(2), 291-301.

Liang, S.W., Chang, Y.W. and Chen, C. (2006a) "Relieving hot-spot temperature and current crowding effects during electromigration in solder bumps by using Cu columns", J. Electron. Mater., 36(10), 1348-1354.

Liang, S.W., Shao, T.L., Chen, C., Yeh, E.C.C. and Tu, K.N. (2006b), "Relieving the current crowding effect in flip-chip solder joints during current stressing”, J. Mater. Res., 21(1), 137-146.

Lin, Y.H., Hu, Y.C., Tsai, C.M., Kao, C.R. and Tu, K.N. (2005), "In-situ observation of the void formation-and propagation mechanism in solder joints under current-stressing", ActaMater., 53(7), 2029-2035.

Lin, Y.H., Lai, Y.S., Lin, Y.W. and Kao, C.R. (2008), "Effect of UBM thickness on the mean time to failure of flip-chip solder joints under electromigration", J. Electron. Mater., 37(1), 96-101.

Lin, Y.L., Chang, C.W., Tsai, C.M., Lee, C.W. and Kao, C.R. (2006), "Electromigration-induced UBM consumption and the resulting failure mechanisms in flip chip solder joints", J. Electron. Mater., 35(5), 10101016.

Liu, A.A., Kim, H.K., Tu, K.N. and Totta, P.A. (1996), "Spalling of Cu6Sn5 spheroids in the soldering reaction of eutectic $\mathrm{SnPb}$ on $\mathrm{Cr} / \mathrm{Cu} / \mathrm{Au}$ thin lms", J. Appl. Phys., 80(5), 2774-2780.

Nah, J.W., Paik, K.W., Suh, J.O. and Tu, K.N. (2003), "Mechanism of electromigration-induced failure in the 97Pb-3Sn and 37Pb-63Sn composite solder joints", J. Appl. Phys., 94(12), 7560-7566.

Nah, J.W., Suh, J.O., Tu, K.N., Yoon, S.W., Rao, V.S., Kripesh, V. and Hua, F. (2006), "Electromigration in flip chip solder joints having a thick Cu column bump and a shallow solder interconnect", J. Appl. Phys., 100(12), 123513.

Shao, T.L., Chen, Y.H., Chiu, S.H. and Chen, C. (2004), "Electromigration failure mechanisms for SnAg3.5 solder bumps on Ti/Cr-Cu/Cu and Ni(P)/Au metallization pads", J. Appl. Phys., 96(8), 4518-4524.

Tu, K.N. (2003) "Recent advances on electromigration in very-large-scale-integration of interconnects", J. Appl. Phys., 94(9), 5451-5473.

Tu, K.N. (2007), Solder Joint Technology, Springer, NewYork, USA, 245-287.

Tu, P.L., Chan, Y.C., Hung, K.C. and Lai, J.K.L. (2001), "Study of micro-BGA solder joint reliability", Microelectron. Reliab., 41(2), 287-293.

Xu, L.H., Han, J.K., Liang, J.J., Tu, K.N. and Lai, Y.S. (2008), "Electromigration induced high fraction of compound formation in $\mathrm{SnAgCu}$ flip chip solder joints with copper column", Appl. Phys. Lett., 92(26), 262104.

Xu, L.H., Pang, J.H.L. and Tu, K.N. (2006), "Effect of electromigration-induced back stress gradient on nanoindentation marker movement in SnAgCu solder joints", Appl. Phys. Lett., 89(22), 221909.

Yeh, E.C.C., Choi, W.J., Tu, K.N., Elenius, P. and Balkan, H. (2002), "Current-crowding-induced electromigration failure in flip chip solder joints", Appl. Phys. Lett., 80(4), 580-582.

Zang, L., Ou, S.Q., Huang, J., Tu, K.N., Gee, S. and Nguyen, L. (2006), "Effect of current crowding on void propagation at the interface between intermetallic compound and solder in flip chip solder joints", Appl. Phys. Lett., 88(1), 012106.

Zeng, K. and Tu, K.N. (2002), "Six cases of reliability study of Pb-free solder joints in electronic packaging technology", Mater. Sci. Eng., R. 38(2), 55-105. 